\title{
A humidity-sensing model for metal-insulator-semiconductor capacitors with porous ceramic film
}

\author{
G. Q. Li \\ Department of Applied Physics, South China University of Technology, Guangzhou, China \\ P. T. Lai ${ }^{\mathrm{a}}$ \\ Department of Electrical and Electronic Engineering, The University of Hong Kong, \\ Pokfulam Road, Hong Kong \\ M. Q. Huang and S. H. Zeng \\ Department of Applied Physics, South China University of Technology, Guangzhou, China \\ B. Li and Y. C. Cheng \\ Department of Electrical and Electronic Engineering, The University of Hong Kong, \\ Pokfulam Road, Hong Kong
}

(Received 6 December 1999; accepted for publication 14 March 2000)

\begin{abstract}
A new physical model for a humidity-sensitive metal-insulator-semiconductor (MIS) capacitor with porous thin film is proposed. The model is used to determine water adsorption isotherm and calculate pore-size distribution of the film. The relative-humidity dependences of the capacitance and resistance of the film were measured. The effects of frequency on the dielectric constant of the film and the current of the MIS structure under various relative humidities were investigated. (C) 2000 American Institute of Physics. [S0021-8979(00)06212-5]
\end{abstract}

\section{INTRODUCTION}

In the development of automatic control techniques, miniaturization of sensors and integration of sensing elements have become important issues. Their realization depends on investigation and exploitation of thin-film sensors on silicon substrates. Perovskite $\left(\mathrm{ABO}_{3}\right)$-type oxides, besides being used as high-permittivity dielectrics in nonvolatile memory, ${ }^{1-3}$ have been extensively studied as sensing materials in recent years. ${ }^{4-11}$ Radio-frequency sputtering or argon ion-beam sputtering commonly found in integrated-circuit fabrication, were used to deposit barium titanate $\left(\mathrm{BaTiO}_{3}\right)^{12,13}$ film on silicon wafer, and strontium lanthanum titanate $\left(\mathrm{Sr}_{1-x} \mathrm{La}_{x} \mathrm{TiO}_{3}\right)^{14}$ or strontium titanate-niobate $\left(\mathrm{SrNb}_{x} \mathrm{Ti}_{1-x} \mathrm{O}_{3}\right)^{15}$ film on $\mathrm{SiO}_{2} / \mathrm{Si}$ substrate. A metalinsulator-semiconductor (MIS) capacitor was then built as a humidity-sensing element. It is well known that these deposited films have a porous structure, ${ }^{12}$ and their capacitances increase with relative humidity due to the fact that adsorbed water in the pores increases the dielectric constant of the materials. In this work, a physical model for water adsorption in porous film is proposed. The effect of adsorbed water on the capacitance of porous film, adsorption isotherm, poresize distribution of the film, and the humidity-sensitivity characteristics of the MIS structure are investigated, with $\mathrm{Sr}_{1-x} \mathrm{La}_{x} \mathrm{TiO}_{3}$ film as an example.

\section{EXPERIMENTS}

$\mathrm{N} / \mathrm{n}^{+}$type silicon epitaxial wafer with (111) orientation and $0.3-0.6 \Omega \mathrm{cm}$ resistivity was used in this experiment.

a) Author to whom correspondence should be addressed. Electronic mail: laip@hkueee.hku.hk
The wafer was cleaned by the standard RCA process $\left(\mathrm{NH}_{4} \mathrm{OH}: \mathrm{H}_{2} \mathrm{O}_{2}: \mathrm{H}_{2} \mathrm{O}=1: 2: 5\right.$; then $\left.\mathrm{HCl}: \mathrm{H}_{2} \mathrm{O}_{2}: \mathrm{H}_{2} \mathrm{O}=1: 2: 8\right)$ with its native oxide removed by a $\mathrm{HF} \operatorname{dip}\left(\mathrm{H}_{2} \mathrm{O}: \mathrm{HF}=10: 1\right)$. $\mathrm{Sr}_{1-x} \mathrm{La}_{x} \mathrm{TiO}_{3}$ film with a $0.8 \mu \mathrm{m}$ thickness was deposited on the silicon substrate by argon-ion-beam sputtering under a vacuum of $1.33 \mathrm{mPa}$ at room temperature, and then the wafers were annealed at $450{ }^{\circ} \mathrm{C}$ for $20 \mathrm{~min}$ in nitrogen. The material chosen for the sputtering target was a sintered-type semiconducting ceramic. Aluminum evaporation and photolithographic processes were used to form a thin-film MIS capacitor, and then the back surface of the device was gold plated to form an ohmic contact (as shown in Fig. 1). Finally, the device was heat treated at $400^{\circ} \mathrm{C}$ for $15 \mathrm{~min}$ in nitrogen, and attached to a header. A high-frequency $(1 \mathrm{MHz})$ capacitance-voltage instrument was used to measure the capacitance of the device under various relative humidities (RHs), and a dc power supply was used to investigate the effects of RH on the resistance of the film. An ac power supply was chosen to measure the current of the device versus $\mathrm{RH}$ under various frequencies.

\section{EQUIVALENT MODEL OF WATER ADSORPTION IN POROUS FILM}

Generally, a humidity-sensitive porous ceramic film is considered to be composed of three portions, i.e., solid ceramic, absorbed and condensed water, and air. The equivalent model of the porous film in Fig. 2 is proposed to describe the humidity dependency of the sensor. Therefore, the total capacitance $C$ of the MIS structure is given as follows:

$$
C=\frac{C_{s} \sum_{i=1}^{n} C_{i}}{C_{s}+\sum_{i=1}^{n} C_{i}},
$$




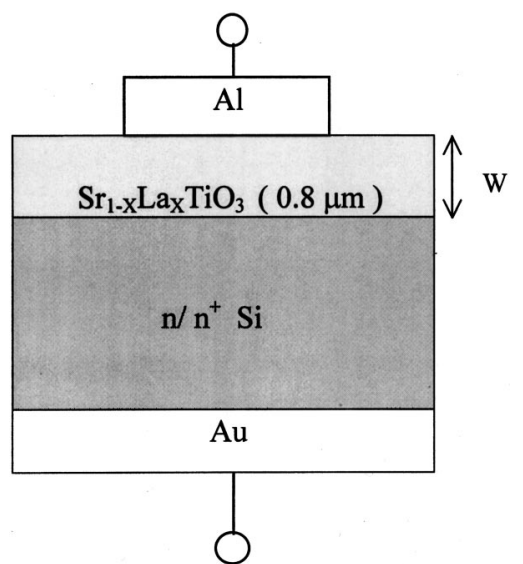

FIG. 1. Cross section of MIS capacitor with $\mathrm{Sr}_{1-x} \mathrm{La}_{x} \mathrm{TiO}_{3}$ film (area of upper electrode is $1.96 \times 10^{-3} \mathrm{~cm}^{2}$ ).

where $n=2$ and 3 for dry and wet conditions, respectively, and $C_{s}=d Q_{s} / d \Psi_{s}$ (charge change with the potential at the silicon surface). Since the surface layer is under accumulation, $C_{s} \gg \sum_{i=1}^{n} C_{i}$. Equation (1) becomes

$$
C=\sum_{i=1}^{n} C_{i}=\frac{\varepsilon_{0}}{W} \sum_{i=1}^{n} \varepsilon_{r i} A_{i},
$$

with $W$ the thickness of the film, $\varepsilon_{0}$ the vacuum pemittivity, and $\varepsilon_{r i}$ and $A_{i}$ the dielectric constants and areas of the corresponding regions shown in Fig. 2, respectively.

For dry condition $(\mathrm{RH}=0 \%)$, the total capacitance of the MIS structure in Fig. 2(a) with a total area $A$ is calculated as

$$
C_{D} \equiv \frac{\varepsilon_{0} A}{W} \varepsilon_{r D}=C_{1}+C_{2}=\frac{\varepsilon_{0} A}{W}\left(\varepsilon_{r 1} N_{1}+\varepsilon_{r 2} N_{2}\right),
$$

where $\varepsilon_{r D}$ is the effective dielectric constant of the porous film under dry conditions, and $N_{1}$ and $N_{2}$ are the area fractions of the two regions, respectively $\left(N_{2}\right.$ is regarded as porosity of the film). Since $\varepsilon_{r 2} \approx 1$ and $N_{1}+N_{2}=1$, Eq. (3) can be written as

$$
C_{D}=\frac{\varepsilon_{0} A}{W}\left[\left(1-N_{2}\right) \varepsilon_{r 1}+N_{2}\right]
$$

or

$$
N_{2}=\left(\varepsilon_{r 1}-\frac{C_{D} W}{\varepsilon_{0} A}\right) /\left(\varepsilon_{r 1}-1\right)=\left(\varepsilon_{r 1}-\varepsilon_{r D}\right) /\left(\varepsilon_{r 1}-1\right) .
$$

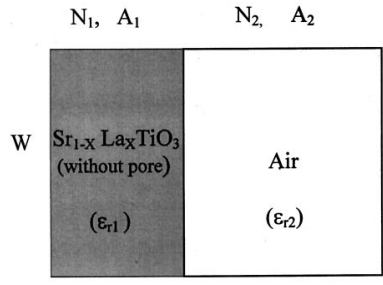

(a)

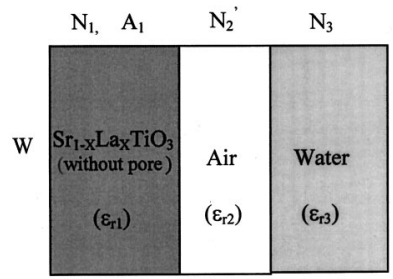

(b)
FIG. 2. Equivalent model of porous film: (a) without water adsorbed; (b) with water adsorbed $\left(N_{1}, N_{2}, N_{2}^{\prime}\right.$ and $N_{3}$ are fractions of the film area).
As can be seen from Eq. (5), $N_{2}$ depends on $\varepsilon_{r D}$ and $\varepsilon_{r 1}$. While $\varepsilon_{r D}$ can be obtained directly from $C_{D}$ [i.e., Eq. (3)], $\varepsilon_{r 1}$ may not be equal to the dielectric constant $\varepsilon_{r 1}^{\prime}$ of the target material. Therefore, a successive approximation method by substituting $\varepsilon_{r 1}^{\prime}$ and $N_{2}$ into Eqs. (5) and (4) is used to calculate $\varepsilon_{r 1}$, and then the total pore volume ( $V$ $=N_{2} A W$ ) in the film can be obtained. For our example of $\mathrm{Sr}_{1-x} \mathrm{La}_{x} \mathrm{TiO}_{3}$ material, measured $\varepsilon_{r 1}^{\prime}, C_{D}$ are 115 and 112 $\mathrm{pF}$ at $1 \mathrm{MHz}$, respectively, and hence $\varepsilon_{r 1}, N_{2}$, and $V$ are calculated to be $102,49.5 \%$, and $7.8 \times 10^{-8} \mathrm{~cm}^{3}$, respectively.

Under a relative humidity of $\mathrm{RH}$, the capacitance of the wet film can be written as

$$
C_{W} \equiv \frac{\varepsilon_{0} A}{W} \varepsilon_{r W}=\frac{\varepsilon_{0} A}{W}\left(\varepsilon_{r 1} N_{1}+\varepsilon_{r 2} N_{2}^{\prime}+\varepsilon_{r 3} N_{3}\right),
$$

where $\varepsilon_{r W}$ is the effective dielectric constant under wet conditions, and $N_{1}, N_{2}^{\prime}, N_{3}$ are the corresponding area fractions shown in Fig. 2(b). With $N_{2}=N_{2}^{\prime}+N_{3}$ and assuming the volume of adsorbed water is $\nu\left(N_{3}=\nu / W A\right)$, Eq. (6) can be written as

$$
\begin{aligned}
C_{W} & =\frac{\varepsilon_{0} A}{W}\left[\varepsilon_{r 1} N_{1}+\varepsilon_{r 2}\left(N_{2}-\frac{\nu}{W A}\right)+\varepsilon_{r 3} \frac{\nu}{W A}\right] \\
& =C_{D}+\frac{\nu \varepsilon_{0}}{W^{2}}\left(\varepsilon_{r 3}-\varepsilon_{r 2}\right) .
\end{aligned}
$$

Since the dielectric constant of water $\left(\varepsilon_{r 3}=81\right)$ is much larger than that of air $\left(\varepsilon_{r 2} \approx 1\right), \nu$ and hence $C_{W}$ increase with increasing RH. Based on Eq. (7), by measuring $C_{D}$ and $C_{W}$ as a function of RH, $\nu$ versus $\mathrm{RH}$ can be obtained.

It is well known that physisorption includes capillary condensation and pore-wall adsorption. Condensation occurs in all the pores with radius up to $r_{k}$ given by the Kelvin equation (contact angle $=0)^{11,16}$

$$
r_{k}=\frac{\gamma \nu_{m}}{R T \ln (1 / \mathrm{RH})},
$$

where $\gamma, \nu_{m}, T$, and $R$ stand for the surface tension, molar volume, absolute temperature, and gas constant, respectively. On the other hand, desorption is determined by a pore radius $r_{k}^{\prime}\left(=2 r_{k}\right) .{ }^{16}$ Since the thickness of adsorbed water on the pore wall is given by the Halsey equation: ${ }^{17,18}$

$$
t=t_{0}\left(\frac{-5}{\ln (\mathrm{RH})}\right)^{1 / 3},
$$

where $t_{0}$ is the thickness of a single adsorption layer, the critical pore radius should be

$$
r=t+r_{k}\left(\text { or } r_{k}^{\prime}\right) .
$$

The logarithmic dependence of $r_{k}$ (or $r_{k}^{\prime}$ ) and $t$ on RH implies that the increase of $\nu, \varepsilon_{r W}$, or $C_{W}$ with RH exhibits strong nonlinearity.

Using the above equivalent model for the $\mathrm{Al} / \mathrm{Sr}_{1-x} \mathrm{La}_{x} \mathrm{TiO}_{3} / \mathrm{SiO}_{2} / \mathrm{Si}$ structure, the film capacitance $\left(C_{F}\right)$ under various $\mathrm{RH}$ can be determined from

$$
C_{T}=\frac{C_{F} C_{\mathrm{OX}}}{C_{F}+C_{\mathrm{OX}}},
$$




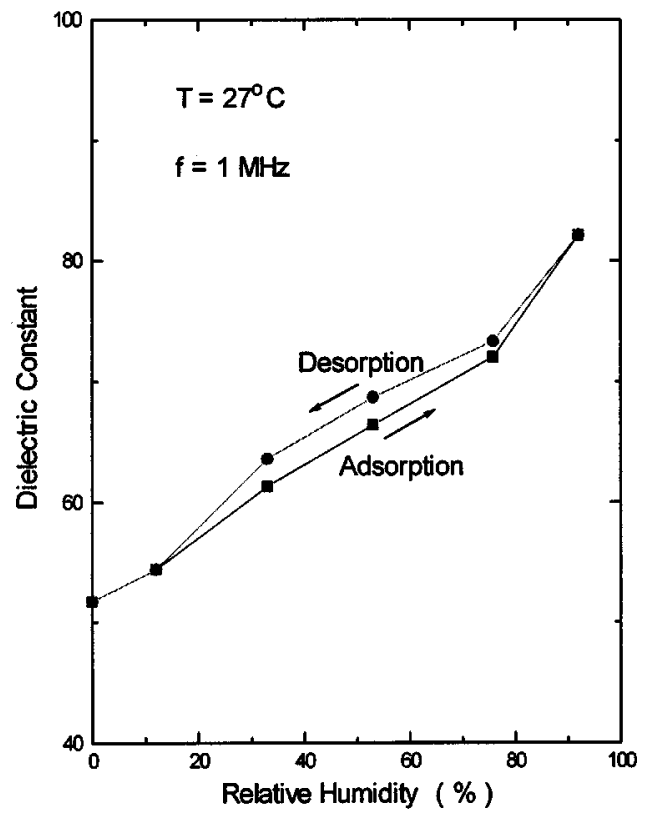

FIG. 3. Dielectric constant of $\mathrm{Sr}_{1-x} \mathrm{La}_{x} \mathrm{TiO}_{3}$ film vs relative humidity at 1 $\mathrm{MHz}$ of test frequency: $(\rightarrow) \mathrm{RH}$ changes from 0\% to 92\% (adsorption branch); $(\leftarrow)$ RH changes from $92 \%$ to $0 \%$ (desorption branch).

where $C_{T}$ is the total capacitance which can be measured at high frequency; $C_{\mathrm{OX}}$ is the capacitance of the $\mathrm{SiO}_{2}$ layer which can be calculated by the device size and dielectric constant of $\mathrm{SiO}_{2}\left(\varepsilon_{r \mathrm{ox}}=3.9\right)$.

\section{RESULTS AND DISCUSSIONS}

The deposited film of $\mathrm{Sr}_{1-x} \mathrm{La}_{x} \mathrm{TiO}_{3}$ and its target material should be an $n$-type semiconducting polycrystalline ceramic, ${ }^{11,19}$ because the atomic radii of $\mathrm{La}^{3+}(0.122 \mathrm{~nm})$ and $\mathrm{Sr}^{2+}(0.125 \mathrm{~nm})$ are nearly the same and hence donor levels are formed in the band gap due to partial substitution of $\mathrm{Sr}^{2+}$ by $\mathrm{La}^{3+}$ in the target material. Moreover, since the substrate is not heated during film deposition and a low temperature is used for postdeposition annealing, single crystal or glass structure should not form in the deposited film. The chemical composition of the film is examined by Auger electron spectroscopy and the composition of $\mathrm{La}$ is found to be about $5 \%$.

\section{A. Effect of relative humidity on dielectric contant of $\mathrm{Sr}_{1-x} \mathrm{La}_{x} \mathrm{TiO}_{3}$ film}

Figure 3 shows that the effective dielectric constant $\left(\varepsilon_{r W}\right)$ of the $\mathrm{Sr}_{1-x} \mathrm{La}_{x} \mathrm{TiO}_{3}$ film increases with RH. The desorption branch lies to the left of the adsorption one as RH changes from low to high and then back, and the maximum hysteresis is about $7 \%$. The hesteresis loop should be related to pore-radius distribution, because according to Eq. (8), the Kelvin radius of desorption is twice that of adsorption under the same RH.

\section{B. Adsorption isotherm and pore-radius distribution of $\mathrm{Sr}_{1-x} \mathrm{La}_{x} \mathrm{TiO}_{3}$ film}

The adsorption isotherm of water for the $\mathrm{Sr}_{1-x} \mathrm{La}_{x} \mathrm{TiO}_{3}$ film could be determined by Eq. (7), i.e.,

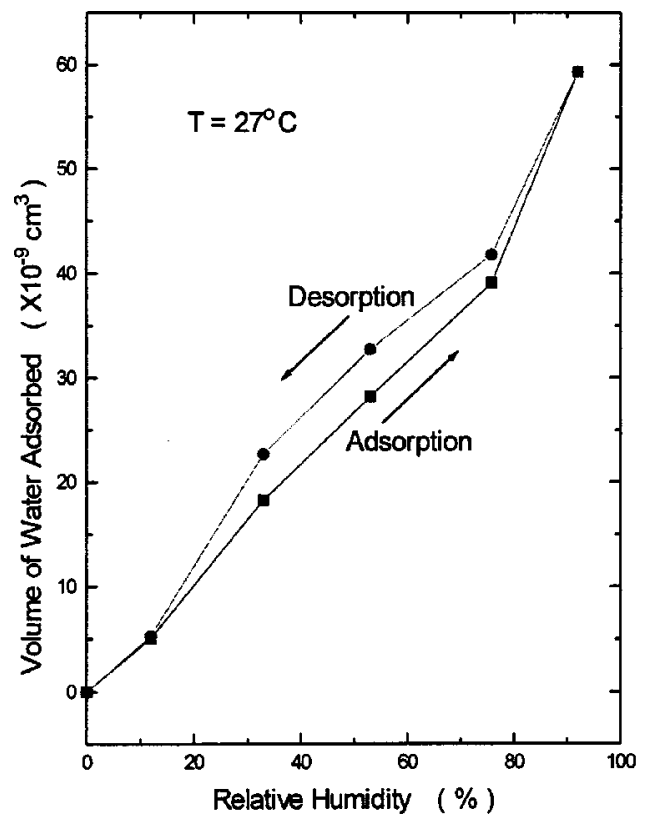

FIG. 4. Adsorption isotherm of water in $\mathrm{Sr}_{1-x} \mathrm{La}_{x} \mathrm{TiO}_{3}$ film (film volume $\left.=A W=1.96 \times 10^{-3} \mathrm{~cm}^{2} \times 0.8 \times 10^{-4} \mathrm{~cm}\right)$.

$$
\nu=\frac{W^{2}}{\varepsilon_{s}} \frac{C_{W}-C_{D}}{\varepsilon_{r 3}-\varepsilon_{r 2}} .
$$

Using the experimental data in Fig. 3, $\nu$ versus $\mathrm{RH}$ can be calculated and is shown in Fig. 4. In the cyclindrical-pore model based on the desorption step, when relative humidity decreases from $\mathrm{RH}_{i-1}$ to $\mathrm{RH}_{i}$ the volumes $\Delta V_{i}$ of pores with radius ranging from $r_{i-1}$ to $r_{i}$ can be calculated by a recurrence formula ${ }^{20-23}$

$$
\begin{aligned}
& \Delta V_{i}=R_{i}\left(\Delta \nu_{i}-2 \Delta t_{i} \sum_{j=1}^{i-1} \frac{1}{F_{i}} \Delta V_{j}+2 \bar{t}_{i} \Delta t_{i} \sum_{j=1}^{i-1} \frac{1}{\bar{r}_{j}^{2}} \Delta V_{i}\right), \\
& \bar{r}_{i}=\frac{1}{2}\left(r_{i-1}+r_{i}\right), \quad \bar{t}_{i}=\frac{1}{2}\left(t_{i-1}+t_{i}\right), \\
& \Delta t_{i}=\left(t_{i-1}-t_{i}\right), \quad R_{i}=\left(\frac{\bar{r}_{i}}{r_{i}-t_{i}}\right)^{2},
\end{aligned}
$$

where $\Delta \nu_{i}$ is the desorption amount of water at the $i$ th desorption step, which includes vaporization of capillary condensation and thinning of the adsorption layer on the wall, with $r_{i}=r_{k i}+t_{i}$ [Eq. (10)].

The increment $\Delta \nu_{i}$ can be determined by the desorption branch of the adsorption isotherm in Fig. 4. In the calculation, $\gamma, \nu_{m}, t_{0}$, and $R$ of water are taken to be $71 \mathrm{dyn} / \mathrm{cm}$ (at $\left.30^{\circ} \mathrm{C}\right), 18 \mathrm{~cm}^{3} / \mathrm{mol}, 3 \AA$, and $8.31 \times 10^{7} \mathrm{erg} / \mathrm{K} \mathrm{mol}$, respectively. Thus $r_{k i}, t_{i}$, and also $\Delta V_{i}\left(r_{i}\right)$ could be calculated by Eqs. (8), (9), and (13). The pore-volume distribution $\left(\Delta V_{i} / \Delta r_{i}\right.$ vs $r$ ) is shown in Fig. 5. The results show that the film has high porosity $\left(\Sigma \Delta V_{i} / A W \approx 47.7 \%\right)$ and present a wide pore-size distribution, which are helpful for improving the humidity sensitivity characteristics. On the other hand, the total pore volume $\left(7.5 \times 10^{-8} \mathrm{~cm}^{3}\right)$ is slightly smaller than the value $\left(7.8 \times 10^{-8} \mathrm{~cm}^{3}\right)$ calculated by Eq. (5), because the RH range from $92 \%$ to $100 \%$ is not included in the experiment. 


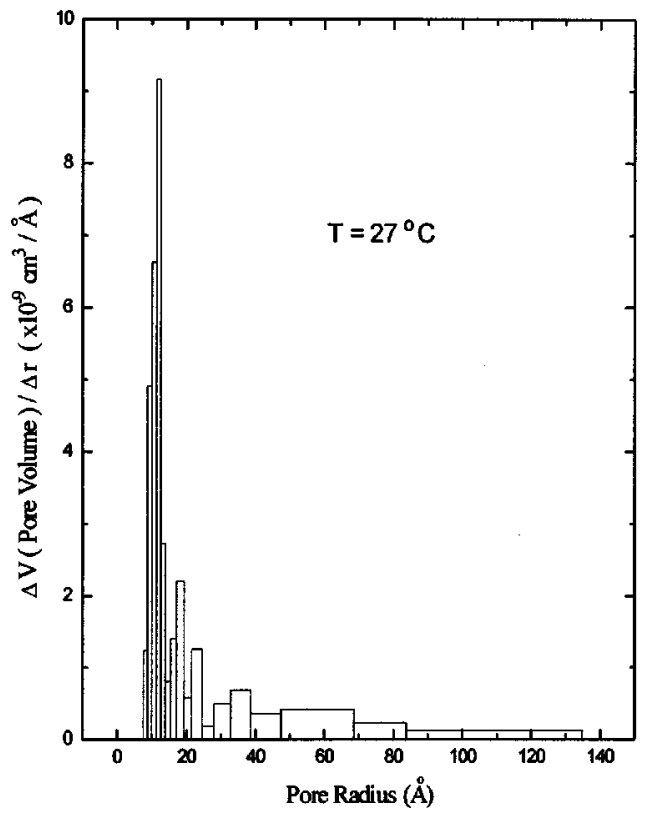

FIG. 5. Pore-volume distribution with pore radius as a parameter.

\section{Frequency effects on humidity sensitivity characteristics of $\mathrm{Al} / \mathrm{Sr}_{1-x} \mathrm{La}_{x} \mathrm{TiO}_{3} / \mathrm{Si}$ structure}

The influence of frequency on the current of the MIS capacitor under various relative humidities is shown in Fig. 6. Theoretically, the current change with increasing frequency is nonmonotonous, and should be a combined effect of frequency increase and dielectric-loss increase on the impedance of the device. Based on a simple parallel resistor $(R)$-capacitor $(C)$ circuit model, the frequency $f$ dependence of the impedance $Z$ of the device is given by

$$
Z=\frac{R}{1+j 2 \pi R C f} \text {. }
$$

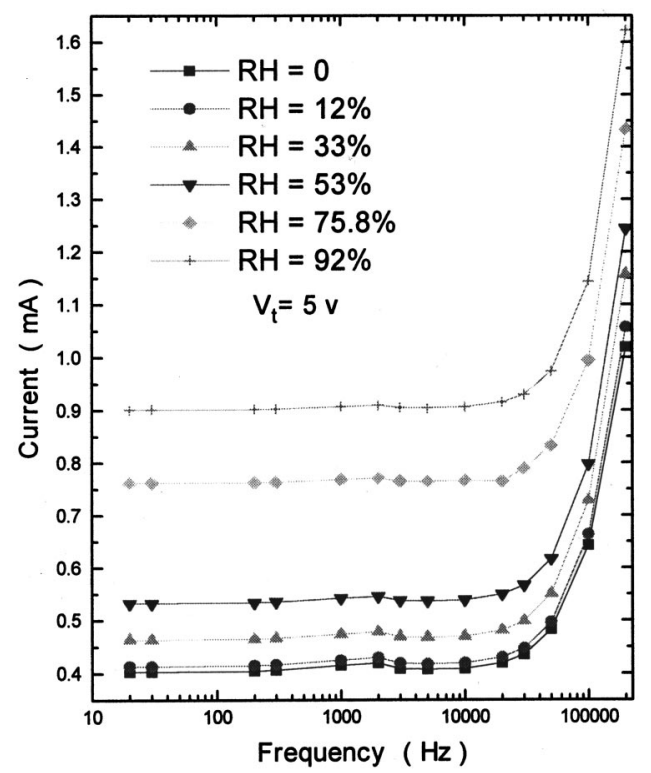

FIG. 6. Current of MIS capacitor vs frequency for various relative humidities (test voltage is in rms value).

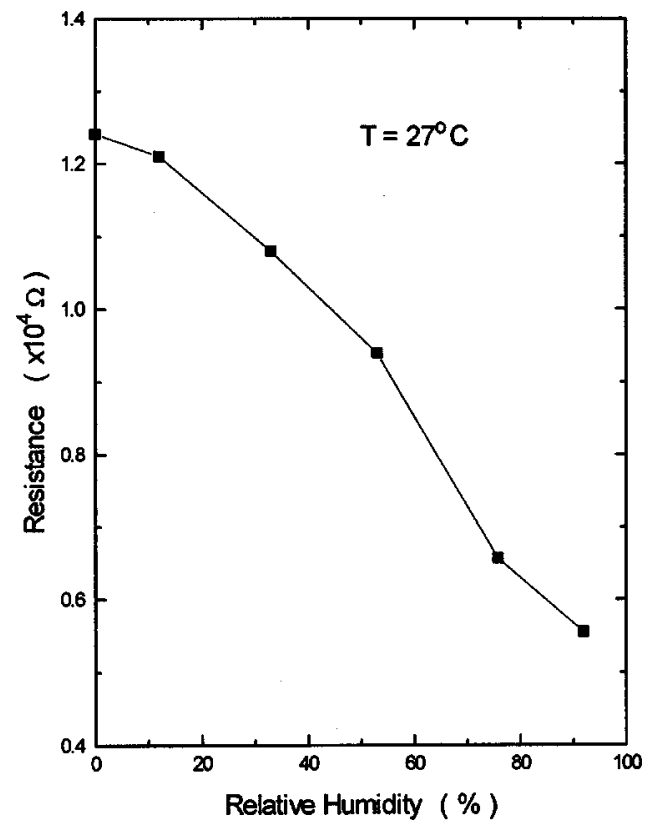

FIG. 7. Resistance of $\mathrm{Sr}_{1-x} \mathrm{La}_{x} \mathrm{TiO}_{3}$ film vs relative humidity.

By measuring $R$ under various RH (as shown in Fig. 7) and calculating $Z$ from Fig. $6, C_{D}$ and $C_{W}$ as a function of $f$ can be obtained. As shown in Figs. 8 and $9, C_{D}$ and $C_{W}$ decrease with increasing frequency, but humidity-induced capacitance $\left(C_{W}-C_{D}\right)$ is almost constant. It reveals that although the dielectric constant of the dry $\mathrm{Sr}_{1-x} \mathrm{La}_{x} \mathrm{TiO}_{3}$ film decreases with frequency (Fig. 10) due to dielectric loss, ${ }^{24,25}$ the water adsorbed in the film does not show any dielectric loss within the experimental frequency range. Therefore, $C_{W}-C_{D}$ either can be determined at low frequency (e.g., $20 \mathrm{~Hz}$ ) by Eq. (13) or directly measured at $1 \mathrm{MHz}$. When $\mathrm{RH}$ changes from $0 \%$ to $92 \%$, the current increases by $130 \%$ under a test voltage of $5 \mathrm{~V}$ with a frequency range from $20 \mathrm{~Hz}$ to $20 \mathrm{kHz}$ at room temperature, but the current change is smaller at higher frequencies, e.g., only $60 \%$ at $200 \mathrm{kHz}$. More experiments dis-

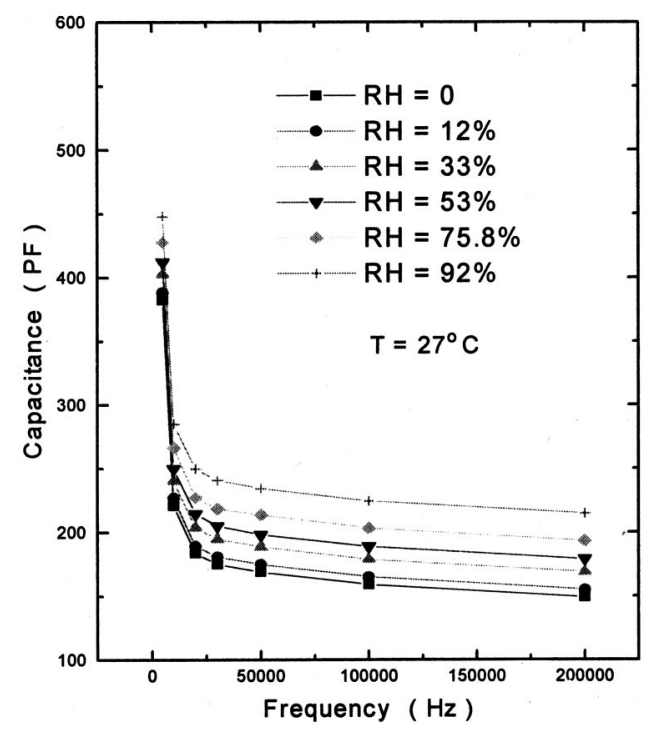

FIG. 8. Influence of frequency on capacitance of $\mathrm{Sr}_{1-x} \mathrm{La}_{x} \mathrm{TiO}_{3}$ film. 


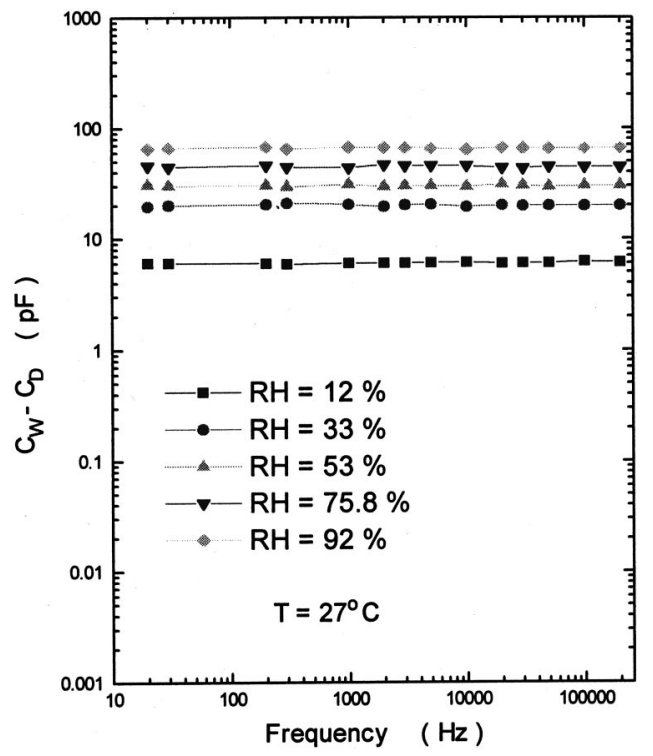

FIG. 9. Humidity-induced capacitance $\left(C_{W}-C_{D}\right)$ vs frequency for $\mathrm{Sr}_{1-x} \mathrm{La}_{x} \mathrm{TiO}_{3}$ film.

cover that the humidity hysteresis of current versus RH generally tends to be smaller with increasing test voltage, possibly due to the fact that Joule heating of the film accelerates evaporation of water.

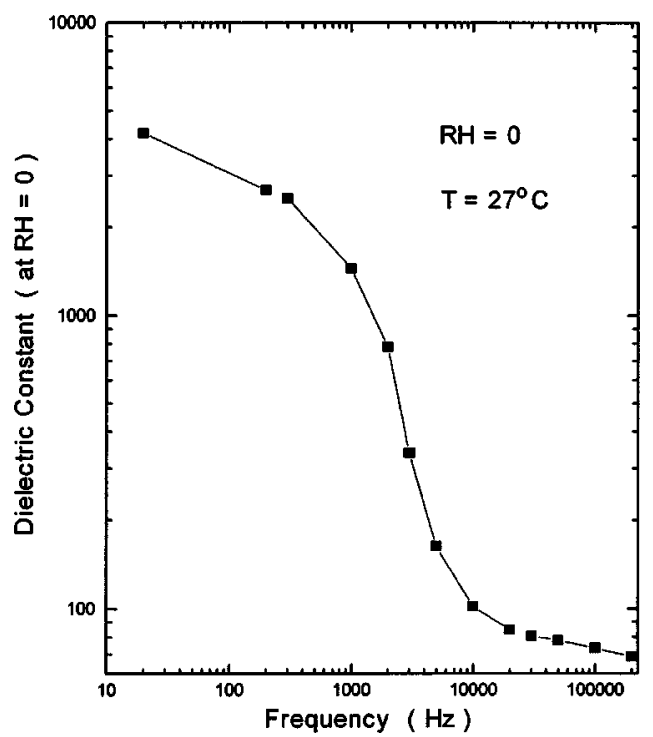

FIG. 10. Effects of frequency on dielectric constant of $\mathrm{Sr}_{1-x} \mathrm{La}_{x} \mathrm{TiO}_{3}$ film without water adsorbed.

\section{CONCLUSIONS}

A new physical model describing the humidity-sensitive MIS capacitor with porous thin film is proposed. The model can be used to determine the water adsorption isotherm and calculate pore-size distribution. Although deposited $\mathrm{Sr}_{1-x} \mathrm{La}_{x} \mathrm{TiO}_{3}$ film presents a dielectric-loss increase at high frequencies, adsorbed water in the film does not enhance this loss for frequencies up to $1 \mathrm{MHz}$. The film exhibits superior humidity-sensitivity characteristics because its dielectric constant increases and its resistivity decreases with increasing $\mathrm{RH}$.

\section{ACKNOWLEDGMENTS}

This work was partially supported by a Sci-Tech Committee Grant of Guangdong, China, a RGC Research Grant, Hong Kong, and a CRCG Research Grant, the University of Hong Kong.

${ }^{1}$ T. Sakuma, S. Yamamichi, S. Matsubara, H. Yamaguchi, and Y. Miyasa, Appl. Phys. Lett. 57, 2431 (1990).

${ }^{2}$ L. H. Parker and A. F. Tasch, IEEE Circuits Devices Mag. 6, 17 (1990).

${ }^{3}$ J. T. Evans and R. Womack, J. Solid-State Circuits 23, 1171 (1988).

${ }^{4}$ J. Hole, J. Slunecko, and M. H. rovat, Sens. Actuators B 26-27, 99 (1995)

${ }^{5}$ U. Lampe, J. Gerblinger, and H. Meixner, Sens. Actuators B 26-27, 97 (1995)

${ }^{6}$ W. Qu and J.-U. Meyer, Sens. Actuators B 40, 175 (1997).

${ }^{7}$ L.-B. Kong and Y.-S. Shen, Sens. Actuators B 30, 217 (1996).

${ }^{8}$ T.-H. Kwon, S.-H. Park, J.-Y. Ryu, and H.-H. Choi, Sens. Actuators B 46, 75 (1998).

${ }^{9}$ S. P. Lee, J. Y. Rim, and Y. K. Yoon, Sens. Mater. 7, 23 (1995).

${ }^{10}$ Y. Shimizu, N. Shimabukuro, H. Arai, and T. Seiyama, Chem. Lett. 7, 917 (1985).

${ }^{11}$ T. Seiyama, N. Yamazoe, and H. Arai, Sens. Actuators 4, 85 (1983).

${ }^{12}$ S. N. Chen, E. S. Ramakrishnan, R. S. Huang, and W. Grannemann, IEEE Electron Device Lett. 5, 452 (1984).

${ }^{13}$ G. Q. Li, P. T. Lai, S. H. Zeng, M. Q. Huang, and B. Y. Liu, Appl. Phys. Lett. 66, 2436 (1995).

${ }^{14}$ G. Q. Li, P. T. Lai, S. H. Zeng, M. Q. Huang, and B. Li, Sens. Actuators A 75, 70 (1999).

${ }^{15}$ G. Q. Li, P. T. Lai, S. H. Zeng, M. Q. Huang, and C. Cheng, Sens. Actuators A 63, 223 (1997).

${ }^{16}$ A. W. Adamson and A. P. Gast, Physical Chemistry of Surfaces, 6th ed. (Wiley, New York, 1997), p. 665.

${ }^{17}$ A. Wheeles, Catalysis 2, 116 (1955).

${ }^{18}$ J. Fraissard and C. W. Conner, Physical Adsorption: Experiment, Theory and Applications (Kluwer Academic, Dordrecht, 1997), p. 133.

${ }^{19}$ R. H. Bube, Photoelectronic Properties of Semiconductors (Cambridge University Press, Cambridge, 1992).

${ }^{20}$ J. M. Yan, Q. Y. Zhang, and J. Z. Gao, Adsorption and Capillary Condensation (Science Publishing House, Beijing, 1986).

${ }^{21}$ A. Wheeles, Catalysis 2, 116 (1935).

${ }^{22}$ S. Brunauer, R. Sh. Mikhail, and E. E. Bodor, J. Colloid Interface Sci. 24, 451 (1967).

${ }^{23}$ E. E. Bodor, I. Odder, and J. Sskalny, J. Colloid Interface Sci. 32, 367 (1970).

${ }^{24}$ D. W. Johnson, L. E. Cross, and F. A. Hummel, J. Appl. Phys. 41, 2828 (1970).

${ }^{25}$ T. Edahiro and F. Yoshimura, Rev. Electr. Commun. Lab. 21, 843 (1973). 